\title{
LA CONSTRUCCIÓN DE TIPOS SOCIALES EN EL COSTUMBRISMO LATINOAMERICANO
}

\author{
Dorde Cuvardic García
}

\begin{abstract}
RESUMEN
En este artículo se analizan los procedimientos descriptivos utilizados en diversos artículos de tipos sociales de la literatura costumbrista latinoamericana. Se define la categoría tipo social y el papel que tuvo el discurso fisiológico en su definición, se analizan las implicaciones ideológicas que permitieron su auge en las prácticas culturales occidentales de inicios del siglo XIX, se describen las convenciones genéricas del artículo de tipos sociales y, finalmente, se someten a análisis algunos artículos latinoamericanos del siglo XIX.

Palabras clave: Literatura costumbrista latinoamericana, tipos sociales, discurso descriptivo.
\end{abstract}

\begin{abstract}
This article analyzes different descriptive methods used in several articles that present social types seen in latinamerican literature of manners. The literary category known as 'social type' is defined as well as the role of the physiological discourse within its definition. Besides this article explores the ideological implications that contribute to the development of social types taking into account Western cultural practices seen at the beginning of the $19^{\text {th }}$ Century. In addition, generic conventions of social types and finally some latinamerican articles from the $19^{\text {th }}$ century are analyzed.
\end{abstract}

Key words: Latinamerican literature of manners, social types, descriptive discourse.

El costumbrismo es un movimiento literario internacional que encuentra en los países latinoamericanos su máximo desarrollo entre 1830 y 1870. El artículo de tipos sociales es uno de sus géneros más importantes. Su función es describir la profesión o función social de un personaje, por lo general situado en una escena, desde la prosopografía y la etopeya.

Dr. Dorde Cuvardic García. Profesor de la Escuela de Filología, Lingüística y Literatura, Universidad de Costa Rica San Pedro, San José, Costa Rica.

Correo electrónico: dcuvardic@yahoo.es

Recepción: 14- 1- 2009

Aceptación: 26- 2- 2009 
Desde estos parámetros descriptivos se analizan algunos artículos de tipos sociales del siglo XIX latinoamericano. En su intención de construir retratos autóctonos, contribuyeron a fortalecer las identidades nacionales de países que se habían independizado recientemente. Así, por ejemplo, Castro Brawson (1966) nos ofrece en su antología de autores costumbristas costarricenses la imagen que estos escritores querían proyectar acerca de Costa Rica en su condición de Estado-nación independiente.

\section{Los tipos sociales}

La construcción de caracteres humanos en Occidente se inicia con Teofrasto. En el 319 antes de Cristo utilizó en los Caracteres su modelo previo de clasificación del mundo vegetal con el objetivo de construir una tipología de los comportamientos humanos. La Bruyère (francés, siglo XVII) supone una continuación de este género literario en la Edad Moderna. Los caracteres, modernizados desde la categoría de los tipos sociales, se constituyeron en base de una pseudociencia, la fisiología, que obtuvo bastante auge en los siglos XVIII y XIX. Desde sus convenciones discursivas se perfilaron los tipos sociales 'pintados' por el costumbrismo.

La fisiología es un vástago tardío de la famosa teoría humoral (ya moribunda en el siglo XVIII), desde la que se formularon los famosos cuatro temperamentos: el colérico, el melancólico, el sanguíneo y el flemático. El objetivo de la fisiología era definir el carácter moral del individuo (etopeya) a partir de sus atributos físicos (prosopografía). Sus premisas son las siguientes: 1) Hay una correspondencia entre la apariencia física (cada parte del cuerpo humano) y el carácter moral de la persona; y 2) una parte del cuerpo humano puede representar al conjunto y constituirse en base para hacer la caracterización global moral del individuo. El rostro, en estas circunstancias, se convierte en la parte más representativa del conjunto, el cuerpo humano.

Las convenciones discursivas de la fisiología fueron muy utilizadas a comienzos del siglo XIX en la práctica literaria costumbrista y en la caricatura con el objetivo de construir los tipos sociales. Los narradores y caricaturistas, en todo caso, reconocieron las 'falsas' pretensiones científicas de la fisiología y esta última fue ocasionalmente parodiada.

Como procedimiento específico, el retrato, sea o no satírico, es una práctica muy importante del siglo XIX que utiliza las convenciones discursivas de la fisiología. Describe un tipo social, por lo general profesional (el político y el cura, por ejemplo).

Debe destacarse la contribución literaria del retrato de tipos sociales en la constitución de la identidad latinoamericana; este procedimiento, propio de la ideología positivista del costumbrismo, busca delimitar los tipos sociales que diferencian a una nación de las demás. Picado Gätgens (1991: 222) explica muy bien esta intencionalidad al afirmar que "el costumbrismo vendrá a ser una manifestación de la popularización del retrato, testimonio para la posteridad de un pueblo original que merecía ser retratado. Una forma de fijar la 'diferencia' respecto a los demás países".

Por su parte, el retrato satírico tiene un mensaje moral, como sucede también en la fábula, que establece una analogía física y de comportamiento entre un ser humano y un animal. Utiliza la hipérbole de los atributos físicos del personaje retratado.

Otras pseudociencias ayudaron al discurso costumbrista a perfilar su proyecto de construcción de tipos sociales. Una de ellas fue la frenología. Su creador fue el alemán Franz Joseph Gall (1758-1828). Procura reconocer los instintos, los talentos y las disposiciones 
intelectuales y morales del ser humano mediante el análisis de la configuración de su cerebro. A través del análisis de la prosopografía de la cabeza y del cerebro de las personas sometidas a estudio, el frenólogo trata de perfilar su etopeya. La descripción frenológica de tipos humanos aparece incluso en la posterior novela realista-naturalista ${ }^{1}$, entre cuyas convenciones descriptivas se encuentran las escenas, también heredadas del costumbrismo, como un mecanismo más de caracterización panorámica de la sociedad burguesa de la segunda mitad del siglo XIX.

\section{Las colecciones de tipos sociales en España y Latinoamérica: La constitución de retratos que perfilan las identidades nacionales}

Parte importante del costumbrismo español e hispanoamericano tuvo por objetivo 'pintar' tipos sociales, tanto en artículos exclusivamente dedicados a su descripción como en aquellos que los sitúan en escenas. Así, por ejemplo, Mariano José de Larra, en El café, no solo se dedica a describir y evaluar las prácticas de sociabilidad que tienen lugar en este espacio público, sino que también perfila algunos de los tipos sociales que protagonizan estas prácticas. En este artículo se 'pinta', por ejemplo, la petulancia de un lechuguino, así como la ignorancia de un médico. El artículo de costumbres El café, en este sentido, es una escena en la que se 'pintan' ciertos tipos sociales.

Estos últimos también aparecieron en colecciones de autoría colectiva. El nacimiento de este proyecto editorial procede de la exaltación del sentimiento de nacionalidad (se trata de describir oficios en trance de desaparición) y de la curiosidad científica por las diversas costumbres de los países; genéricamente, las colecciones de tipos sociales se producen en el momento de transición del romanticismo al realismo, se comercializan por entregas -mediante suscripción-, van acompañadas de ilustraciones, tienen una visión totalizadora (panorámica) de la sociedad y participan en sus páginas desde grandes autores hasta autores de escaso valor (Margarita de Ucelay 1951).

En España, la colección más famosa fue Los españoles pintados por sí mismos, publicada en 1848, en 2 tomos, con 98 tipos sociales y acompañada de ilustraciones; como ejemplo, la clase media cuenta con el apartado Las pequeñas profesiones decorosas, llenas de raquítica pretensión y angustiosa realidad proletaria, que incorpora los siguientes artículos: "El empleado"; "El pretendiente"; "El covachuelista"; "El escribano"; "El retirado"; "El cesante"; "El dómine"; y "La vida del militar". En España también se publicó, entre otras, la colección Los valencianos pintados por sí mismos.

En Latinoamérica, las colecciones de tipos sociales más famosas son Las habaneras pintadas por sí mismas en miniaturas (1847), Los cubanos pintados por sí mismos (1852) y Los mexicanos pintados por sí mismos (1855). En estas colecciones los artículos también se ilustran con grabados.

Dos colecciones tardías, dedicadas a tipos sociales femeninos, son Las mujeres españolas, portuguesas y americanas, en tres volúmenes (1872, 1873 y 1876) ${ }^{2}$, yLas mujeres españolas, americanas y lusitanas pintadas por sí mismas $(1882)^{3}$.

Como podemos apreciar por la fecha de publicación, los últimos proyectos editoriales costumbristas se comercializan cuando comienza a triunfar el realismo-naturalismo en tierras latinoamericanas, incluso a las puertas del modernismo. 


\section{Propuesta metodológica de análisis de los artículos de tipos sociales}

El corpus que se investiga proviene de la antología de Julián Moreiro, Costumbristas de Hispanoamérica. Cuadros, leyendas y tradiciones (Madrid: Editorial Edaf 2000). Se analizan artículos costumbristas seleccionados previamente por un antólogo guiado por el criterio de la representatividad (tipos latinoamericanos reconocibles) y la diversidad (femeninos y masculinos, conductas, oficios en trance de desaparición...). Aparece una selección 'panorámica' de tipos sociales latinoamericanos.

Los artículos que aparecen como objeto de estudio son los siguientes: del argentino Juan María Gutiérrez, El hombre hormiga; del cubano José Victoriano Betancourt, La solterona; del mexicano Ignacio Ramírez, La coqueta; del mexicano Juan de Dios Arias, El evangelista; del colombiano Juan de Dios Restrepo, Los pepitos; del puertorriqueño Julio L. de Vizcarrondo, El hombre velorio; del venezolano Fermín Toro, Un romántico; del venezolano Francisco de Sales Pérez, El baladrón; del peruano Pedro Paz Soldán y Unanue, Los poetas; del argentino Domingo Faustino Sarmiento, Caracteres argentinos, capítulo segundo de Facundo. Civilización o barbarie; del cubano Gaspar Betancourt Cisneros (El lugareño), Escena de lenguas; y del puertorriqueño Manuel Fernández Juncos, El tigre. Se situarán los tipos sociales analizados en el proyecto de construcción de la identidad nacional.

La intención de los artículos de tipos sociales es perfilar a grandes rasgos un grupo social, un colectivo. Afirman Todorov y Ducrot (1986: 261- 262), que el tipo se encuentra caracterizado por su estatismo y que, en él, "los atributos no sólo permanecen idénticos, sino que también son muy escasos y con frecuencia representan el grado superior de una cualidad o un defecto (por ejemplo, el avaro que sólo es avaro, etc.)." Se trata de describir lo específico (el individuo) por medio de lo general (el tipo social). Se define, en todo caso, socio-históricamente: el tipo social remite a un perfil profesional típico de una sociedad o a las prácticas de sociabilidad cotidianas de los individuos.

Un tipo social se construye en términos descriptivos, tanto física como psicológicamente. La prosopografía es el procedimiento de construcción del tipo social en su descripción física; la etopeya remite a su descripción psicológica. Recordemos, junto con del Caño (1999: 129130), que "(s)i la descripción destaca el aspecto externo del personaje (detalles físicos, manera de vestir, objetos vinculados a su proceder o modo de ser habitual) se denomina prosopografía; si, por el contrario, hace referencia a su carácter psicológico, a su manera de pensar, a sus aficiones, trabajo u ocupación, estaremos ante una etopeya" (en cursiva en el original). Se utiliza, sobre todo, la operación descriptiva de la aspectualización, es decir, la asignación de atributos a un objeto o ser humano.

Debe precisarse que el retrato del tipo social se formula no solo mediante la descripción de sus atributos físicos y psicológicos, sino también de las acciones típicas o recurrentes que pueda adoptar en su profesión u oficio.

\section{Análisis de los artículos}

\subsection{Tipos masculinos parásitos: El Baladrón y el Pepito}

En la literatura costumbrista latinoamericana, al igual que en la española, se representan en bastantes ocasiones tipos masculinos burgueses improductivos; sobre todo, la crítica satírica se dirige a los jóvenes que 'malgastan' su tiempo. 
En el caso español podemos recordar Los calaveras, dos artículos publicados por Mariano José de Larra. El calavera es aquel joven que, para combatir su aburrimiento, gasta bromas pesadas a los demás con sus ocurrencias. Utilizando con intencionalidad satírica procedimientos discursivos propios de las ciencias naturales, Larra establece dos especies principales de calaveras: los domésticos y los silvestres. Esta última clase, a su vez, se subdivide en 'especies' menores. Es un tipo social caracterizado desde la etopeya por su poca aprensión (no concede importancia hacia 'el qué dirán') y por tener un talento natural (es decir, se nace 'calavera').

En el costumbrismo hispanoamericano también hay un gran interés por los tipos sociales económicamente improductivos. En sociedades que necesitan establecer sólidas bases comerciales e industriales, los parásitos de ciertos sectores sociales son objeto de sátira.

Uno de estos tipos improductivos es el baladrón o fanfarrón, descrito por el venezolano Francisco de Sales Pérez (Justo): "Me voy a ocupar en hacer el bosquejo de un ciudadano que no se ocupa en nada; de un ser que gana su vida amenazando la ajena" (2000: 278). Francisco de Sales distingue el baladrón moderno del antiguo. Este es uno de los pocos casos donde se reconoce una evolución histórica del tipo social, frente al típico procedimiento de representarlo sincrónicamente. En el artículo Los pepitos, del colombiano Juan de Dios Restrepo, también aparece un alejamiento del discurso sincrónico, típico de las taxonomías preparadas por las ciencias naturales en la primera mitad del siglo XIX.

Francisco de Sales, en primer lugar, perfila al baladrón antiguo, tipo social que podemos equiparar al 'majo' dieciochesco. No comete delitos, sino solo 'travesuras'. El baladrón antiguo es un tipo social de la época de la colonia, anterior a la independencia, hijo de una sociedad patrimonial:

\footnotetext{
Aquel era un mocetón medio criollo y medio andaluz, rico por lo regular, y botarate, simpático a las mujeres, repugnante a los maridos, espada pronta, jamás puñal; mal ciudadano si se quiere, pero gallardo en la agresión y travieso sin maldad. No permitía que nadie pagara donde estaba él, a trueque de que nade se creyera más valiente y de que todo el mundo estuviera dispuesto a aceptar los compromisos que él provocara. Era buen bailador, billarista y coleador (Sales Pérez 2000: 477).
}

En cambio, el baladrón contemporáneo es un tipo social negativo para el 'buen' funcionamiento de una sociedad que quiere modernizarse. Es militar pretencioso: improductivo en su profesión, se escuda en la autoridad para aprovecharse, con ostentación, de los ciudadanos. En el baladrón contemporáneo se pueden distinguir las siguientes especies: el del palacio de gobierno, el de las cantinas y el del mercado público o de plaza de barrio (este último es el único descrito en su vestimenta). El baladrón contemporáneo también es caracterizado desde la etopeya. Su principal atributo es la 'insolencia'.

En Los pepitos, de Juan de Dios Restrepo, se afirma que el pepito cuenta como precedente al cachaco, un calavera colombiano. Es un joven elegante soltero (prosopografía) siempre identificable por sus travesuras, por su humor y por llevar la contraria de los demás (etopeya).

Todo tipo social, a diferencia del carácter, se encuentra socio-históricamente definido (desarrolla su actividad en una sociedad específica) y, como tal, puede llegar a desaparecer y ser sustituido, en ocasiones, por otro tipo social. Así le sucede al cachaco, sustituido por el pepito a raíz de la modernización de la sociedad colombiana:

Chistes escogidos, ocurrencias afortunadas, elegancia en el vestir, modales finos, aventuras galantes, calaveradas de buen tono; todas o algunas de estas circunstancias forman la esencia y son las credenciales de este tipo original. El matrimonio y los puestos oficiales dan al traste con su carrera. Una esposa es lastre demasiado pesado para su vida desordenada y ligera de bohemio, y los destinos públicos, 
embarazando su lengua y su pluma, apagan dos de sus cualidades características, que son la crítica constante y la oposición. Sin chispa y travesura no hay cachaco posible. A todo hombre joven y soltero no se puede dar este título: es necesario merecerlo, y en vano han pretendido tan honroso dictado muchos ricos palurdos y provincianos imbéciles. Pero ¡oh fragilidad de las cosas humanas!, este tipo original [...] ha sido absorbido, derrocado, eclipsado y amilanado por el pepito: el pepito es dueño de la situación (en cursiva en el original) (Restrepo 2000: 179).

Restrepo recurre a la escena para caracterizar al pepito, sucesor del cachaco. Este último era ingenioso y exhibía una actitud crítica inteligente. En cambio, desprovisto de toda actitud mordaz, el pepito solo galantea con las hijas de los burgueses (Restrepo 2000: 182-183). Aunque semejantes en su juventud y en su soltería, el cachaco y el pepito son diferentes en sus costumbres y en su actitud crítica.

\subsection{Tipos sociales 'acaparadores': El Tigre y el Hombre Hormiga}

En El tigre, Manuel Fernández Juncos tipifica a un parásito social que se aprovecha de sus conciudadanos. En este caso, la aspectualización, que utiliza satíricamente el discurso zoológico, se presenta integrada en la misma denominación del tipo social (véase también el caso de el hombre hormiga, analizado más adelante). Como sucede con el pepito (que tiene al cachaco como precedente), el tigre puertorriqueño también aparece como sucesor de un tipo social previo, el cacique o hacendado rico:

\footnotetext{
El tigre viene a ser el sucesor del cacique, en las comarcas empobrecidas donde ya no quedan elementos propios para la subsistencia de este último. Era cacique en ellos un hacendado rico, y fundábase en esta última condición el prestigio de que aparecía rodeado y la influencia decisiva que solía ejercer entre sus convecinos. Hoy los hacendados están de baja, y lo está, por consiguiente, el número de caciques (Fernández Juncos 2000: 403).
}

El tigre queda caracterizado desde la etopeya moral como vanidoso, fatuo, soberbio e ignorante. No es un hacendado, sino un comerciante o abastecedor local con vínculos políticos. Mantiene actitudes monopolistas y clientelistas.

El artículo no solo recurre a la descripción etopéyica. También se recurre a la narración con el objetivo de describir las actividades típicas de este tipo social. Se describe su enfrentamiento con el alcalde del pueblo y su viaje a la capital (el tigre relata a los lugareños sus actividades en la ciudad).

A diferencia del resto de los artículos de la compilación que analizamos, El tigre termina con una recapitulación de sus atributos etopéyicos y prosopográficos.

El hombre hormiga, de Juan María Gutiérrez, es otro ejemplo de utilización del inventario, típico del discurso de las ciencias naturales, con pretensiones satírico-costumbristas. El enunciador llega a elogiar al naturalista Georges Louis Leclerc, conde de Buffon, autor de una Historia Natural: "iQuién tuviera el don de observar y la elocuencia de Bufón para describir a nuestro héroe!" (Gutiérrez 2000: 58). El discurso zoológico interviene en la descripción costumbrista desde el encuadre metafórico para ofrecernos el retrato del hombre hormiga, individuo avaro y trabajador que acumula riquezas. Como señala Moreiro (2000: 35), en El hombre hormiga se realiza "una crítica del ser avaro y egoísta que va siempre a su afán, carece de patriotismo y solidaridad y dedica su vida por entero a la tarea de aumentar su peculio."

Se utiliza la metáfora de la hormiga para designar la principal característica del tipo social humano analizado: trabajar para acumular. A inicio del artículo se justifica esta comparación: 
No es fábula lo que vamos a escribir, aunque lo parezca a primera vista por el título: el hombre hormiga, no quiere decir tanto como el hombre y la hormiga, sino un viviente que tiene los hábitos y el instinto de aquel pequeñísimo insecto (Gutiérrez 2000: 57).

Las fábulas asignaban atributos humanos a los animales para criticar satíricamente la psicología y el comportamiento de los primeros. En el artículo de Gutiérrez, en cambio, se describe la conducta de la hormiga, previamente humanizada, para tipificar un comportamiento humano. A la altura del siglo XIX estas correspondencias entre el ser humano y los animales ya se encontraban tan tipificadas que otros géneros literarios, como el artículo de costumbres, podían hacer uso de ellas e incorporarlas en sus convenciones descriptivas.

Además de prestarse una gran atención a su infancia (el niño hormiga), este tipo social también es descrito, en términos prosopográficos, en sus actividades 'comerciales' típicas.

\subsection{Tipos femeninos misóginos: La Solterona y la Coqueta}

La literatura costumbrista de los tipos sociales es descaradamente misógina. Recordemos que también tiene esta actitud la literatura satírica del siglo XVIII, tanto española como hispanoamericana. En los artículos costumbristas de tipos femeninos se practica desde el sarcasmo cruel $^{4}$.

Tipo social común a todos los países hispanohablantes es la coqueta. No pertenece a los tipos sociales que distinguen a una nacionalidad de las demás. Es un tipo social bastante retratado. Recuérdese el caso del artículo La coqueta, de Ramón de Navarrete, incorporado al primer tomo de Los españoles pintados por sí mismos, donde se declara al inicio: "Véase como de todos los males de la humanidad, tiene la culpa la coquetería de las mugeres" (2002 [1843], I: 69).

El mexicano Ignacio Ramírez también redactó un artículo bajo el título La coqueta, donde pretende describir a este tipo social como el entomólogo a su insecto:

\footnotetext{
La coqueta es una mujer que se encapricha en conquistarse adoradores con las armas de un atractivo que le ha negado el cielo, pero que su vanidad y su malicia saben aparentarlo con numerosos y admirables artificios; en consecuencia, para conocerla es necesario estudiar detenida y separadamente sus faltas, sus artificios y sus adoradores (la cursiva es añadida) (Ramírez 2000: 281).
}

Se trata de un análisis de la coquetería como práctica social, como práctica de sociabilidad protagonizada por la mujer burguesa. Se interpreta como una serie muy codificada de imposturas 'viciosas' que emprende la mujer en sus relaciones con los hombres. Además, este tipo femenino, que exhibe gracias 'impuestas', es enemiga de la mujer que cuenta con gracias 'naturales'.

El narrador establece la causa de la coquetería; en primer lugar, la necesidad de esconder el 'defecto' físico de la fealdad. Se pretende ocultar una verdad negativa tras las falsas apariencias:

Fuente abundante de coquetería es la falta de hermosura; pero ninguna mujer se juzga enteramente fea; siempre es un pero, un solo defecto el que atormenta su vanidad y donde tropieza la admiración con que contempla el soberbio conjunto de sus gracias. De aquí provienen los secretos del tocador y las posturas estudiadas; de aquí la lucha eterna y dudosa entre la fealdad y el lujo (Ramírez 2001: 282).

Para el autor del artículo, una segunda causa de coquetería surge de la necesidad que tiene la mujer, en el espacio burgués, de ser apreciada por su dinero, no por su personalidad:

La coquetería más ridícula es la que tiene su origen en la falta de dinero; la mujer con pretensiones de rica no quiere cautivar con su valor personal ni juzga que para ser amada es preciso se amable (Ramírez 2001: 282). 
Mientras que la primera se convierte en coqueta para esconder la fealdad, la segunda es coqueta como medio para alcanzar o mantener un estatus social. En ningún momento el escritor, mediante un análisis crítico, asigna como causa de este comportamiento el sistema de normas y de roles públicos y privados que el patriarcado 'impone' a la mujer burguesa.

Este tipo social, según el autor, se dedica al consumo suntuario. El sociólogo Thorstein Veblen, en su Teoría de la clase ociosa, nos permite explicar la aparición de la coqueta en el marco de la ideología patriarcal burguesa: el consumo suntuario y el ocio de la esposa, o incluso de la querida, contribuye a fortalecer la reputación pública del burgués. Cuando Ramírez (2001: 283) señala que los amantes de la coqueta ven en ella un simple objeto de lujo debemos comprender este enunciado en el marco de este proyecto patriarcal burgués. Atenta a que la opinión pública no la llame cursi (por exhibir ropas y objetos de segunda clase como si fueran de primera), emprenderá prácticas de consumo suntuario. Es así como la coquetería, en la representación literaria de tipos femeninos y personajes en el artículo de costumbres y en la novela realista (véase, por ejemplo, en La de Bringas, de Galdós), se vincula sociológicamente a la cursilería ${ }^{5}$.

Dentro de un encuadre científico naturalista, Ramírez establece diferentes tipos de coquetería: la de las mujeres enfermizas, la de las asustadizas, la de las apasionadas, la de las que afectan mirar con desprecio a los jóvenes que no pertenecen a su familia...

Otro artículo caracterizado por la misoginia es La solterona, de José Victoriano Betancourt. Papel construido e impuesto por el patriarcado, este último sistema ideológico, sin embargo, lo propone como rol elegido por la misma mujer:

Quedarse para tía es cosa que depende las más veces de las mismas mujeres, salvo los casos de fealdad que hacen de ella la personificación de uno de los preceptos del Decálogo (Betancourt 2000: 261).

La propuesta moralizadora queda explícita cuando, en el último párrafo del artículo, el narrador evalúa negativamente el papel de la soltería desde el eje positivo de la maternidad. Debe considerarse la función moralmente correctora de estos artículos: el lector real y el implícito de los escritores costumbristas es femenino. Por ejemplo, Gaspar Betancourt Cisneros, en Escena de lenguas, afirmará: "lectora queridísima que me diste el tema de esta Escena y me encargaste que fuese pintor leal" (2000: 237).

La interferencia del discurso entomológico en la construcción del tipo social se hace presente en este artículo. Se desvaloriza a la mujer mediante la animalización. En La solterona (2000: 254), afirma el narrador:

\footnotetext{
Los naturalistas, al menos que yo sepa, no han clasificado aún esta entidad jamona y descontentadiza (...) Aunque yo la he observado mucho, no he podido aún clasificarla: considerándola criandera nata de los sobrinos, podría colocársela en la familia de las abejas, en la cual hay cierto número de ellas, destinadas únicamente a la crianza de las larvas. También pudiera considerársela como pariente de las auras tiñosas.
}

Los tipos sociales se integran muchas veces en escenas. Este procedimiento descriptivo se realiza en La solterona:

\footnotetext{
Para conocer a fondo a la solterona vamos a buscar un tipo y ponerle en escena. Doña Desesperada se nos presenta a pedir de boca; pero vosotros, mis queridos lectores, no la conocéis, y es fuerza que yo os ponga en relaciones con ella (2000: 255).
}

La solterona, en este artículo, se encuentra situada en diversas escenas. En un bautizo, hace de serpiente con un hombre, don Crisóstomo, para echarle la zarpa como marido, mientras que este último hace creer a la solterona, doña Desesperada, que quiere casarse, para divertirse un costa de ella. 
El ridículo es el principal atributo de la conducta de la solterona: prefiere la compañía de grupos de jóvenes mujeres, emprende una toilette excesiva... Además, es una figura autoritaria: impide que las sobrinas se casen. Excluye a los demás de la sexualidad que ella evita.

Betancourt logra vislumbrar la causa de la afición de la solterona a la murmuración, al chismerío: "Doña Desesperada, para llenar las largas horas de su soltería, murmura de todo cuanto ve" (Betancourt 2000: 259). En una sociedad patriarcal que incentiva la soledad de las mujeres que no se casan a cierta edad, la murmuración es un mecanismo compensatorio; sin embargo, este autor no llega a 'ver' que la soltería y el tedio que conlleva, junto con otras limitaciones que tiene la mujer burguesa y pequeño-burguesa en la prácticas de la sociabilidad pública, provienen de la ideología patriarcal. Por lo demás, recordemos que el ennui femenino, referido a la mujer recluida en el interior burgués, es uno de los grandes temas de la novela realista decimonónica.

En otras ocasiones, las causas de la soltería que Betancourt ofrece no son, realmente, causas de este comportamiento: afirma que la soltera prefiere la soltería por orgullo, por necedad y por coquetería (Betancourt 2001: 261). El orgullo, la necedad y la coquetería no son causas de aparición de la solterona, sino tres de sus atributos, desde la enunciación patriarcal sostenida en este artículo.

Escena de lenguas (Gaspar Betancourt Cisneros -El lugareño- ) es otro artículo misógino. El articulista critica a las mujeres por hablar demasiado en diferentes espacios sociales. Existen en Camagüey, según el narrador, las mujeres regañonas, las murmuradoras, las chismosas (con las especies -que el narrador define como subgéneros- de las habladoras y de las mentirosas) y, por último, la gemela o jimagua.

\subsection{El Gaucho}

Caracteres argentinos, de Domingo Faustino Sarmiento, es el segundo capítulo de Facundo. Civilización o barbarie, en el que se encuentran representados diferentes tipos de gauchos: el rastreador, el baqueano, el gaucho malo y el cantor.

El gaucho rastreador se encuentra definido por su actividad; queda 'pintado' desde la etopeya como "personaje grave, circunspecto, cuyas aseveraciones hacen fe en los tribunales inferiores. La conciencia del saber que posee le da cierta dignidad reservada y misteriosa" (Sarmiento 2000: 68). Interpreta las huellas del ganado. Es un semiótico que analiza uno de los tres tipos de signos definidos por Peirce: los índices o índex. Sarmiento, como instancia enunciativa, llega a decir que la interpretación de las huellas del ganado es "ciencia vulgar" (Sarmiento 2000: 68). Este tipo social queda perfilado desde su aptitud distintiva: el rastreo e interpretación de huellas de animales y de presos fugados ( $c f r$. con el episodio del análisis de las huellas del caballo en Zadig, novela de Voltaire).

El baqueano, quien conoce la pampa palmo a palmo, también identifica, como el rastreador, huellas naturales (infiere la proximidad del agua) y humanas, pero es ante todo un guía: en tiempos de guerra orienta a los generales y anuncia la proximidad del enemigo; en tiempos de paz, conduce a los viajeros. En el ámbito de la etopeya es como el rastreador: "es un gaucho grave y reservado" (Sarmiento 2000: 70). Su actividad también queda tipificada, como en el caso anterior, como ciencia (Sarmiento 2000: 72); más específicamente, el baqueano es "el topógrafo más completo, el único mapa que lleva un general para dirigir los movimientos de su campaña" (Sarmiento 2000: 70). 
El gaucho malo también es pintado en sus acciones típicas, sobre todo en sus 'hazañas' ante la ley. Desde la etopeya es descrito como 'misántropo'. Al igual que los demás tipos de gaucho, conoce la pampa detalladamente; este saber, que nuevamente el narrador define como ciencia, lo aplica a su conducta cotidiana.

El gaucho cantor es el último tipo formulado por Sarmiento. Queda caracterizado como bardo (el poeta épico):

\footnotetext{
El gaucho cantor es el mismo vate, el bardo, el trovador de la Edad Media, que se mueve en la misma escena, entre las luchas de las ciudades y del feudalismo de los campos, entre la vida que se va y la vida que se acerca. (...) El cantor está haciendo, candorosamente, el mismo trabajo de crónica, costumbres, historia, biografía, que el bardo de la Edad Media, y sus versos serían recogidos más tarde como los documentos y datos en que habría de apoyarse el historiador futuro, si a su lado estuviese otra sociedad culta, con superior inteligencia de los acontecimientos, que la que el infeliz despliega en sus rapsodias ingenuas (Sarmiento 2000: 75).
}

Figuras clave en la historia literaria de las identidades latinoamericanas, los gauchos de Sarmiento quedan revestidos de un aura de nobleza, de grandeza, en su dura supervivencia frente a la naturaleza.

\subsection{Tipos literarios: El Romántico y el Poeta}

Un romántico, del venezolano Fermín Toro, no es propiamente un artículo donde se retrate un tipo social, en el que se describan sus acciones típicas, sino una escena dialogada. Esta modalidad discursiva, en todo caso, es suficiente para caracterizar al tipo social, parodiado por los escritores costumbristas, situados por otra parte en el propio movimiento romántico.

El romántico quijotesco es un ejemplo de aquellas personas que se encuentran tan imbuidas de las modas culturales, que finalmente acaban por asumir el comportamiento de los personajes literarios. Hay muchos textos literarios que parodian las actitudes románticas, tanto en Latinoamérica como España. En este último país podemos nombrar El romanticismo y los románticos, de Mesonero Romanos, publicado en septiembre de 1837 en el Semanario Pintoresco Español, artículo en el que se parodia el fanatismo del sobrino del escritor hacia un Romanticismo de cartón piedra, afectadamente pasional ${ }^{6}$. Asimismo, puede mencionarse otro caso de quijotismo, en este caso desde el teatro hispanoamericano. Nos referimos a la comedia Contigo pan y cebolla (1833), del mexicano Manuel Eduardo Gorostiza, sobre una joven, Matilde, que se considera heroína romántica: solo se casará con su pretendiente cuando éste último finja ser pobre?

Incorporada en la compilación que nos ocupa en este artículo, también es una parodia romántica el artículo en verso Los poetas, del peruano Pedro Paz Soldán y Unanue (Juan de Arona), donde se representa humorísticamente el poeta romántico atormentado, un estereotipo en la época de su publicación.

Más universal es el tipo retratado por José Zorrilla en El poeta (2002 [1843]: 150- 158), artículo incorporado en el segundo tomo de la colección Los españoles pintados por sí mismos. En cambio, una subespecie es El poeta bucólico (2002 [1843] 501- 502), de Mesonero Romanos (El Curioso Parlante), de esta última colección. 


\subsection{Modos de vivir que no dan de vivir: El Evangelista y el Hombre Velorio}

El evangelista, del mexicano Juan de Dios Arias, es uno de los escasos tipos profesionales de la antología. Es el escribano público que se dedica a redactar cartas y documentos jurídicos para personas analfabetas o que, sin serlo, buscan textos literarios originales para ofrecerlos a la amada. Pertenece a esos oficios que Larra define como modos de vivir que no dan de vivir. Su modo de vida es coyuntural. El evangelista ha desempeñado y desempeñará otros oficios:

nuestro evangelista es por lo regular de condición humilde, pertenece a la clase democrática como los pescadores en tiempo de Augusto, y aunque no haya sido pescador de profesión, porque no es necesaria una profesión para ser evangelista, el nuestro en cuestión fue por lo menos aprendiz de barbero, coime de billar, sacristán, o a lo más sargento retirado sin el goce de fuero y uniforme (Arias 2001: 303).

Desde el procedimiento de la prosopografía es un tipo social caracterizado en su cotidianeidad laboral. Queda situado en una escena, descrita por un narrador diegético que decide observar, acompañado de su amigo, el trabajo del evangelista: Don Hilarión "me citó para que fuésemos a examinar de cerca al escribiente público" (Arias 2001: 306). Durante el transcurso de esta escena, atiende a una mujer cuyo marido acaba de salir de la cárcel; a una anciana que pretende librar a su hijo del servicio militar; a un criado que busca versos de celos $\mathrm{y}$ amor; $\mathrm{y}$ a un barrilero que busca poemas para felicitar a un compadre por su cumpleaños.

Se trata de un oficio muy extendido en la época y, como tal, fue incorporado en las representaciones literarias y visuales. En la colección Los españoles pintados por sí mismos (18431844) también aparece este tipo social. Al igual que su versión mexicana, desempeña distintos oficios para sobrevivir. Nos referimos al artículo El escribiente memorialista, escrito por Antonio García Gutiérrez. Además, fue representado a mediados del siglo XIX por el gran caricaturista francés Honoré de Daumier. En la actualidad no ha desaparecido del espacio socio-cultural latinoamericano; recuérdese, en este caso, su presencia en película brasileña Estación Central.

Por último, el hombre velorio es un artículo del puertorriqueño Julio L. de Vizcarrondo dedicado a los individuos que se cuelan en los velorios de los funerales para obtener algunos beneficios, sobre todo comida. Este tipo de conductas todavía perviven en las representaciones culturales del siglo XXI, como lo demuestra la película Wedding Crashers (Los rompebodas, 2005).

En cambio, en el artículo que nos ocupa, escrito a mediados del siglo XIX, la instancia enunciativa se encarga de destacar que el tipo social descrito se desenvuelve en una época pretérita. Recuérdese que, en la mayor parte de los casos, la intención de los escritores costumbristas era la 'pintura' de tipos sociales populares en trance de desaparición. Las colecciones no dedican mucho espacio a los tipos sociales burgueses o pequeño-burgueses de la naciente sociedad capitalista independiente (un ejemplo es Los españoles pintados por sí mismos, donde aparecen escasos tipos burgueses y pequeño-burgueses).

Es tipificado prosopográficamente en su modo de ser habitual (saludar a la llegada del velorio, buscar la comida, informarse sobre la identidad de los presentes, fumar, beber licor, comer bizcochos; indicar, ya casi al amanecer, la necesidad de alistar café y pan caliente; convertirse en alcahuete de los jóvenes que flirtean...). Se encuentra descrito en una escena, la del velorio: aparece al atardecer y se marcha al amanecer. También es tipificado en su vestimenta:

camisa y pantalón «de andar de noche»; un redingot de irlanda cruda, un par de chinelas, un sombrero de Panamá en el cuerto grado de consunción; y en vez del chafarote de marras, un bastoncito de naranjo, cieniguillo o Juan caliente; completando su ajuar un pañuelo de bolsillo de grandes dimensiones y grandes flores (de Vizcarrondo 2000: 398). 
Este es uno de los escasos artículos de la antología donde el signo vestimentario contribuye a describir al tipo social. Al depender de una conducta fundamentada en el engaño, en el disimulo, este indicador social es fundamental en su desempeño.

No solo los tipos sociales se organizan en subespecies en el discurso costumbrista. Ocasionalmente también se establece una clasificación de las prácticas sociales. En el artículo de Julio L. de Vizcarrondo, el velorio queda tipificado como práctica social: existen velorios de muerto grande, velorios de angelito y velorios de palo seco.

\section{Conclusión}

La mayor parte de los artículos de tipos sociales que hemos analizado realizan una crítica moral de actitudes humanas impuestas por la sociabilidad pública burguesa, como sucede con los tipos sociales femeninos. Solo algunos de ellos son exclusivamente retratos de profesiones u oficios.

Los escritores costumbristas representan el tipo social en sus condiciones históricas específicas. Los países latinoamericanos, cuyas condiciones económicas y culturales se diferencian de las europeas, producen tipos sociales locales. Así, por ejemplo, el gaucho es típico de la pampa argentina y, como tal, es retratado por la literatura gauchesca; el tigre, por su parte, es típico de Puerto Rico; el baladrón, de Venezuela; el pepito, de Colombia.

La segmentación del tipo en subtipos suele practicarse en algunos de los artículos, procedimiento común del discurso de las fisiologías. Así ocurre en la descripción del gaucho o de la coqueta.

La mayor parte de los artículos se fundamentan en tipos ya aparecidos en la literatura satírica del siglo XVIII. El cachaco y el pepito tienen como precedente al petimetre, tipo social afrancesado perfilado previamente en la literatura del siglo XVIII (José Cadalso en sus Cartas Marruecas; Melchor Gaspar de Jovellanos en la Sátira a Arnesto -también llamada Sátira sobre la mala educación de la nobleza-).

Los tipos sociales femeninos se retratan desde una elevadísima misoginia. El costumbrismo sigue los modelos próximos de la sátira barroca y neoclásica. Se describen tipos de mujer sexual y económicamente 'improductivos' (como es el caso de la coqueta o de la solterona). Se critica desde el patriarcado un tipo social que esta misma ideología se ha encargado de crear. Por su parte, los tipos sociales masculinos, económicamente improductivos y sexualmente productivos, aunque también reciben una crítica moral, esta última se enmarca en el ámbito de la 'reprimenda' o reconvención, más que en el de la 'condena', como sucede en el caso de los tipos sociales femeninos.

\section{Notas}

1. Aunque se constituye en un caso residual, ya que participa en el movimiento naturalista, en Los pazos de Ulloa, de Emilia Pardo Bazán, encontramos una descripción frenológica de Sabel:

-Sus ojos azules, húmedos y sumisos, su color animado, su pelo castaño que se rizaba en conchas paralelas y caía en dos trenzas hasta más abajo del talle, embellecían mucho a la muchacha y disimulaban sus defectos, lo pomuloso de su cara, lo tozudo y bajo de su frente, lo sensual de su respingada y abierta nariz (la cursiva es añadida) (Pardo Bazán 2001: 109). 
Otro ejemplo de la misma novela procede de la descripción de un cazador:

y en el rostro, afeitado y enjuto y de enérgicas facciones rectilíneas, una expresión de encubierta sagacidad, de astucia salvaje, más propia de un piel roja que de un europeo (la cursiva es añadida) (Pardo Bazán 2001: 99).

2. El subtítulo de esta colección nos declara los temas que se 'pintan': Tales como son en el hogar, en los campos, en las ciudades, en los templos, en los espectáculos, en el taller y en los salones. Descripción y pintura del carácter, costumbres, trajes, usos, religiosidad, belleza, defectos, preocupaciones y excelencias de la mujer de cada una de las provincias de España, Portugal y América, e ilustrada por los más notables artistas españoles y portugueses.

3. El subtítulo también no declara los temas 'pintados': Estudio completo de la mujer en todas las esferas sociales. Sus costumbres, su educación, su carácter. Influencia que en ella ejercen las condiciones locales y el espíritu general del país al que pertenece. Obra dedicada a la mujer por la mujer y redactada por las más notables escritoras hispano-americanas-lusitanas bajo la dirección de la señora doña Faustina Sáez de Melgar, e ilustrada con multitud de magníficas láminas dibujadas por don Eusebio Planas.

4. Como recuerda Schoentjes (2001: 192) al diferenciar el sarcasmo de la ironía, "en la medida en que no da rodeos, se confunde a veces con el invectiva y el insulto. Sea directo o indirecto, el sarcasmo es siempre más grosero que la ironía porque es a la vez más visible y más maligno."

5. Paradójicamente, la instancia enunciativa que representa la cursilería en el costumbrismo y en el realismo no deja de ser cursi. Por ejemplo, Galdós, a través de la instancia enunciativa que utilizaba en sus novelas, ha sido criticado como un escritor cursi. Podría pensarse, en cambio, que los escritores costumbristas y realistas, cuando utilizan una escritura cursi, son sutilmente irónicos. Mediante una escritura irónica pretender criticar la cursilería. Se podría trabajar más sobre este aspecto de la 'escritura' costumbrista y realista en el futuro.

6. Como señala Rodríguez Gutiérrez (2004: 233-237) al referirse a la presencia de este tipo de parodias en el cuento español, el romanticismo que se está criticando es el de los espectros y suicidios. Y Montesinos (1960: 54) afirmará:

Las sátiras de Mesonero, como las de otros costumbristas antirrománticos, tendieron siempre a ridiculizar exageraciones que nada tenían que ver con la escuela, o insensateces y majaderías que del romanticismo no tomaban sino grotescos detalles, gestos y actitudes extremosos.

\section{Bibliografía}

Alcoba, Santiago (coord.). 1999. La oralización. Barcelona: Ed. Ariel.

Bal, Mieke. 1995. Teoría de la narrativa (Una introducción a la narratología). Madrid: Editorial Cátedra.

Castro Rawson, Margarita. 1966. El costumbrismo en Costa Rica. San José, Costa Rica: Editorial Costa Rica. 
del Caño, Amelia. 1999. "Los géneros orales informativos”. En: Alcoba, Santiago (coord.). Barcelona: Editorial Ariel, 109- 68.

Ducrot, Oswald y Tzvetan Todorov. 1986. Diccionario enciclopédico de las ciencias del lenguaje. México D.F.: México.

García Gutiérrez, Antonio. 2002 [1843]. "El escribiente memorialista". En: VV. AA. Los españoles pintados por sí mismos [Edición facsimilar]. Madrid, España: Editorial Visor, 47- 51.

Graham, John. 1979. Lavater's essays on physiognomy. A study in the history of ideas. Berne: Peter Lang.

Larra, Mariano José de. 1968. "El café”. Artículos completos. (Recop., pról. y notas de Melchor de Almagro San Martín). Madrid, España: Editorial Aguilar, 119- 132.

1968. "Los calaveras". Artículos completos. (Recop., pról. y notas de Melchor de Almagro San Martín). Madrid, España: Editorial Aguilar, 287- 300.

La Bruyére. 1947. Los caracteres. México D.F., México: Ediciones de la Universidad Nacional de México.

Mesonero Romanos. 2002 [1843]. "El poeta bucólico”. En: VV. AA. Los españoles pintados por sí mismos [Edición facsimilar]. Madrid: Visor Libros, 501- 502.

Montesinos, José F. 1960. Costumbrismo y novela. Ensayo sobre el redescubrimiento de la realidad española. Madrid: Editorial Castalia.

Moreiro, Julián (antólogo). 2000. Costumbristas de Hispanoamérica. Cuadros, leyendas y tradiciones. Madrid: Editorial Edaf.

Navarrete, Ramón de. 2002 [1843]. "La coqueta”. En: VV. AA. Los españoles pintados por sí mismos [Edición facsimilar]. Madrid: Visor Libros, 69- 76.

Oviedo, José Miguel. 1997. Historia de la literatura hispanoamericana. 2. Del romanticismo al modernismo. Madrid: Alianza Editorial.

Pardo Bazán, Emilia. 2001. Los pazos de Ulloa. Madrid: Editorial Cátedra.

Picado Gätgens, Olga. 1991. "Imagen y costumbrismo: tradición metatextual”. Káñina. 15 (1- 2): 221- 226. 
Poe, Edgar Allan. 1969. Cuentos. Tomo I. San Juan, Puerto Rico: Editorial Universitaria. Universidad de Puerto Rico.

Rodríguez Gutiérrez, Borja. 2004. Historia del cuento español. Madrid: Iberoamericana.

Sánchez de Horcajo, J.J. y Octavio Peña (comps.). La sociología. Textos fundamentales. Madrid: Ediciones Libertarias/Prodhufi.

Schoeentjes, Pierre. 2003. La poética de la ironía. Madrid: Editorial Cátedra.

Shookman, Ellis. 1993. The faces of physiognomy: interdisciplinary approaches to Johann Caspar Lavater. Columbia: Camdem House.

Teofrasto. 1943. Los caracteres. Buenos Aires, Argentina: Editorial Sopena Argentina.

Ucelay Da Cal, Margarita. 1951. Los españoles pintados por sí mismos (1843-44). Estudio de un género costumbrista. México: Colegio de México

Varios Autores. 2002. Los españoles pintados por sí mismos. Madrid, España: Editorial Visor.

Thorstein Veblen. 1996. “El ocio ostensible”. En: Sánchez de Horcajo, J.J. y Octavio Peña (comps.). Madrid: Ediciones Libertarias/Prodhufi, 611-626.

Wechsler, Judith. 1982. A Human Comedy: Physiognomy and caricature in $19^{\text {th }}$ century Paris (Foreword by Richard Sennet). London: Thames and Hudson. 